UCID. 18635

\title{
A Double-sided Electron-Beam Generator for \\ KrF Laser Excitation
}

\author{
L. Schlitt \\ J. Swingle
}

May, 1980

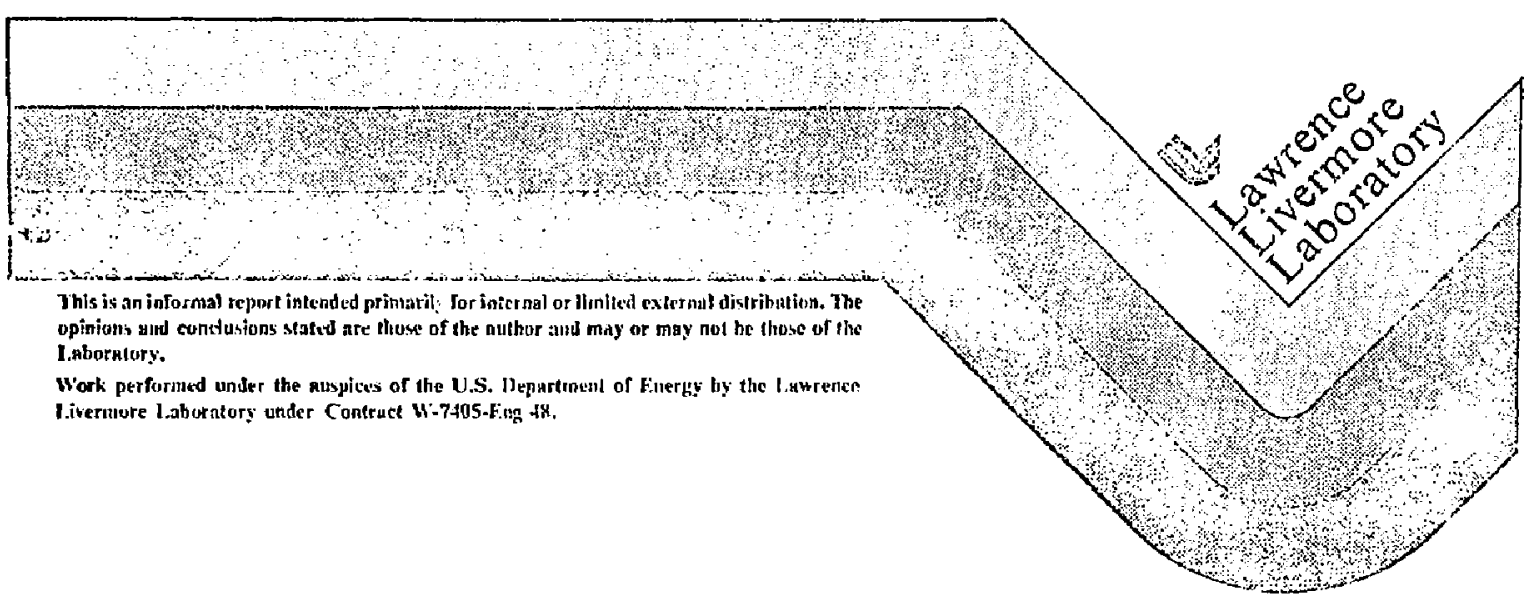




\title{
A Double-sided Electran-Beam Generator for \\ KrF Laser Excitation
}

\author{
L. Schlitt and J. Swingle \\ University of California Lavrence Livermore National Laboratory \\ Livermore, CA 945 i0
}

(415) $422-6159$

\begin{abstract}
Several laser systems excited by electron beam have been identified as candidates for panp sources for laser fusion applications. The electron beam generators required must be compact, reliable and capable of synchronization with other system components. A KrF laser producing a minimum output of $25 \mathrm{~J}$ was needed for the RAPIER (Raman Amplifier Pumped by Intensified Excimer Radiation) system. A double-sided electron beam system was designad and constructed specifically for this purpose and has produced $>35 \mathrm{~J}$ of KrF output. Each of the two electron beam machines in the system operates with an rms jitter of $0.4 \mathrm{~ns}$ and together occupy $23.5 \mathrm{~m}^{2}$ of floor space. The successful operation of this laser has engendered requests for a description of the engineering details of this system. This document contains a brief description of the design issues and a full set of engineering drawings for this krF laser amplifier.
\end{abstract}

* Wori performed under the auspices of the U. S. Department of Energy by the Lawrence Livermore National Laboratory under contract number U-7405-ENG-48.

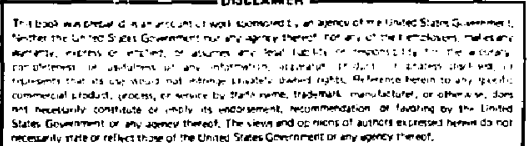

i 


\title{
A Double-sided Electron Beam Generator for \\ KrF Laser Excitation
}

\author{
L. Schlitt and J. Swingle \\ University of California Lawrence Livermore National Laboratory \\ Livermore, CA 94550
}

(415) $422-6159$

\section{Introduction}

Several laser systems excited by electron beam have been identified as candidates for pump sources for laser fusion applications. The electron beam generators required must be compact, reliable and capable of synchronization with other system components. A KrF laser produsing a minimum output of $25 \mathrm{~s}$ was needed for the RAPIER (Ranan Amplitier Pumped by Intensified Excimer Radiation) system. A double-sided electron beam system was designed and constructed specifically for this purpose and has produced $>35 \mathrm{~J}$ of KrF output. Each of the two electron beam machines in the system operates with an rms jitter of $0.4 \mathrm{~ns}$ and together occupy $23.5 \mathrm{~m}^{2}$ of flaor space. The successfui operation of this laser has engendered requests for a description of the engineering details of this system. This document contains a brief description of the design issues and a full set of engineering drawings for this krF laser amplifier.

* Work performed under the auspices of the U. 5. Departinent of Energy by the Lawrence Livermore National Laboratory under contract number W-7405-ENG-48. 
The reader is cautioned against the use of the attached drawings for replication of the system without the aid of informed electrical and mechanical engineering support. There are severai regiolss within the machine where the design tolerances are critical and other regions where they are not. No attempt has been made within this document to distinguish between critical ancl non-critical designs and dimensions. In addition, this machine is a research device, designed and operated at paraneters near design linits. Performance and reliability may depend on intangibles not specifically associated with the mechanical design. The reader should anticipate that substantial debugging and redesign activity may be required to obtain acceptable performance from this system.

A list of the engineering drawings and the drawings themselves are attached as Appendix I.

\section{System Design}

The choice of electron energy is bounded from above by the combination of laser medium composition, maximum operating pressure, and desired output aperture, and from below by anode foil losses and the desire to keep the system impedance as large as possible. An output voltage of $300 \mathrm{kV}$ was selected as a reasonable operating point. A Monte Carlo calculation of energy daposition was performed for a $10 \times 10 \mathrm{~cm}$ aperture by $50 \mathrm{~cm}$ long ce 11 filled with 2 atm of a mixture of $96 \%$ argon and $4 \%$ krypton gases. The cell was bounded on two sides by $13 \mu$ thick Havar foils and thick aluminum walls on the remaining sides. The calculation indicated that $30 \%$ of the energy incident on the foil is deposited in the laser medium. The spatial distribution of energy deposited as viewed in the plane transverse to the laser axis is shown in Fig. 1 for two 
electron beams incident from opposite sides of the volume. Contours of equal energy deposited per unit volume are plotted for $80 \%$ and $90 \%$ of the peak value demonstrating that. pumping is uniform to within $\pm 10 \%$ of the mean over nearly the entire volume, Allowing for a $20 \%$ loss to the anode foil support structure not inclucled in the Monte Carlo calculation, the cvarall efficiency from the electron beam diode to energy depositod in the gas is $25 \%$. Assuming that $5 \%$ of the deposited energy is converted to laser output, $500 \mathrm{~J}$ must be deposited requiring $1000 \mathrm{~J}$ from each electron beam which for a 60 ns pulse length inplias a machine impedance of about $5 \Omega$. The diode current of $60 \mathrm{kA}$ results in a current density of $120 \mathrm{~A} / \mathrm{cm}^{2}$ in the dinde. The required inpedance and pulse length made a pulse charged water dielectric transmission line the obvious choice far forming the output pulse.

Since the A amplifier is to be used in a variety of pulse compression and stacking schemes involving synchronization with several other system conponents, timing jitter hat to be kept to an absolute minimum. Thus a triggered output switch was chosen for the putse forming line. The positive charged Blumiein configuration was selected for the pulse forming line because of the accessibizity of the output switch for triggering and because the lower charge voltage permitted the design of a more compact four stage $400 \mathrm{kV}$ Marx generatar. The Blumlein itself is a cylindrically symmetric triax with an outer diameter of $36 \mathrm{~cm}$. Extensive nulierical calculations of electric field distributions in the outrut switch, puise forming line and diode were used to minimize peck alectric stress. The output switch consists of two annular main electrodes with a disc shaped midplane trigger efectrode. The interelectrode gap is $1 \mathrm{~cm}$ and operates at $300 \mathrm{kV}$ when pressurized with 100 psig of $\mathrm{SF}_{6}$ gas. The trigger electrode is resistively biased at ane-half the charge 
voltage and the trigger pulse is coupled to it through an oil-insulated ring capacitor. The charge current to the intermediate conductor flows along a rod which passes through this entire assembly as shown in Fig. 2.

The diode insulator is a flat lucite disc with the inner and outer line conductors shaped so that the electric field lines meet the insulator surface at $45^{\circ}$. The cathode mounting hardware is constructed of 15 cin diameter aluminum pipe housed is: a chamber made from $22 \mathrm{~cm}$ dianeter tubing in order to minimize diode inductance estimated to be $<30 \mathrm{nh}$. The cathode mounting hardware was polished to permit operation without spurious emission at the resulting $115 \mathrm{k} V / \mathrm{cm}$ electric fields.

\section{Blumlein Tests}

The Marx generator, pulse forming line, and output switch were tested and characterized prior to the completion of the diode and laser cell designs. A radjal copper sulfate load resistor was constructed for the output of the line. The pulse shape obtained with the triggered output switch is shown in Fig. 3 . The risetime indicates a switch inductance of 12 nh which implies that a minimum of two current carrying channels are formed when the output switch is tr iggered.

Obtaining low jitter operation of the output switch was crucia? to the success of the A amplifier system. A trigger generator was constructed from barjum titanate capacjtors pulse charged from the Blumlein iarx. These capacitors were discharged by an over-volted spark gap into a $4 \mathrm{~m}$ long $50 \Omega$ cable. The pulse ampljtude delivered to a $50 \Omega$ load resistor was $-150 \mathrm{kV}$ with a 10 ns risotime and an exponential decay giving 50 ns FWHA. After characterization the $50 \Omega$ load resistor was removed and the cab?e connected to the 
coupling capacitor of the output switch trigger electrode. A series of 20 shots were fired (one prefired) with the resuits shown in Fig. 4 . The resulting standard deviation of the time between the arrival of the trigger pulse at the switch and the arrival of the output pulse at the load was 0.4 ns. This demonstrated the capabilities of the output switch though at present a different scheme is being used to trigger the system as described belaw.

\section{Electron Beam Tests}

Obtaining uniform emission from a cold cathode in eTectric fields $<200 \mathrm{kV} / \mathrm{cm}$ requires some gross field enhancement. A hexayaricl stainiess steel honeycomb material was selected for the cathode. The individual cells of the materiat are $3 \mathrm{~mm}$ across and are made of 75 it thick foil. Electron pinhole images of the cathode indicate that an average of $3-1$ emission sites are created at each cell resulting in acceptably uniform fllumination of the anode plane.

The two nested coaxial transmission lines which wake up the $A$ amplifier Blumlein are charged in series with the innermost line charged throight an inductor located near the diode insulator. During charging the voltage drop across this inductor atso appears across the diode. To limit this prepulse voltage, the charging time for the line was set at $1 \mu \mathrm{sec}$, the value of this inductor reduced ta 21.5 th and a $100 \Omega$ resistor placed in parallel with the inductor. This combination of paraneters results in a voltage suing on the cathode from $+35 \mathrm{kV}$ to $-20 \mathrm{kV}$ during the charging of the line. These voltages are sufficiently large to cause unwanted emission from excessively field enhanced regions of the diode. To control this emission which can lead to a shorted diode by the time the output pulse arrives, the foil support structure is covered with an aluminized Kapton foil to shield it from the $+35 \mathrm{kV}$ portion of the prepulse electric field and the honcycomb cathode is surroundad by a 
stainless steel band to reduce the large field onhancement at the cathode corner. This combination shown in Fig. 5 eliminates emission in the diode during the charging of the line.

The output pulse delivered to the diode is shown in Fig. 6 . The voltage pulse which differs markedly from that obtained with a resistive load droops principally due to the low value of changing inductance required to minimize prepulse. The inductor and resistor are in parallel with the diode during the output pulse and subtract $2750 \mathrm{~J}(12 \%)$ from the available cutergy. Plasma closure in the diode also contributes to the voltage dronp. The shorter current pulse and slower current risetime suggest a delay in foination of the cathode plasma.

The characteristics of the electron bean after passing through the combination of anode foils and support structure were examined. The spatiat profiles of the bean as measured with a tilm dosimeter are shom in fig. 7 . The beam energy measured with a carbon calorimeter was 650 :50 a for each bean which is consistent with the anount of energy needed to produce $500 \mathrm{~J}$ deposited in the laser mediun.

\section{Triggering Systêns}

The initial laser experiments require only that the two clectron beall machines fire within a few naroseconds of each other. Rather than construct a separate trigger generator, the scheme shom in Fig. g(a) was used. A pair of $50 \Omega$ cables were pulse charged from each Marx. Both cables were connected to a single spark gap located midwa between the two machines. This coninon switch operated in an over-volted mode shorting both calbles and similtaneous?y praducing tringer pulses for both nachines. The rms jitter for this systen has been verified as <0, i ns. 1 Hoce recently this combon gap has been 
replaced with a trigatron gap which is triggerei by a pusse formed with a laser triggered spark gap. ${ }^{1}$ (Fig. $8(\mathrm{~b})$ ) The overall stunciard deviation from the arrival of the laser pulse to the arrival of the voltage pulse at the diode is $0.4 \mathrm{~ns}$.

\section{Summary}

An electron bean system has bean designed and constructed to pump a kif laser which has produced $>35 \mathrm{~J}$ of optical energy. The tuno illichines which make up the systein have been synchronized with oach otiner and with another laser system with a measured rins jitter of $0.4 \mathrm{~ns}$. This approach should parmit the construction of larger, more complex elerton bean pumped laser systens emproying purse stacking and pulse compression techniques.

\section{References}

1. R. Rapoport, private commication.

\section{Acknowledgments}

The author gratefully acknowledges contributions of T. Petach, D. Roberts, D. Biggert, J. Taska and W. Smilej who assisted in design, construction, and testing of the $A$ amplifier system.

$$
\text { Sill: }
$$

"This report was nrepured as an aceolan or wort sponserred by the Uniced States Gowernment. Weither the United Sid:es nor the Uniter Stals:

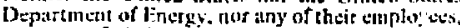
nor any of their coptractors subcontructura, or theit emplogess, malies anj wisraaty, exprest on

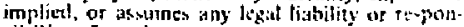
sibility for the accuratey. esmpletents at usefulness of any information, apparatus, prothut or process diselssed, or espreverts that is use wouls not infrimge privitcly-owned rights:"

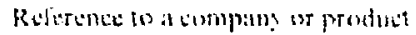
name doen nest fumply aproval at acommendation of the penduct by the lativersity of Calitionis on the

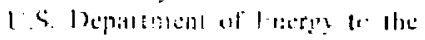
solusion af usters that may bet suidablt. 
Appendix A

Dy dl:ing No.

MA78-103940-0A

AAM7B-108477-00

AAA78-108017-0A

AAA73-108948-30

MA79-108029-00

AAA78-1018951-00

NM73-116930-00

MAAZB-10893?-00

MMA73-1089??-00

12473-108933-c0

A4n80- $103905-00$

A2A79-1065?5-0A

1AA79-106523-00

MA79-106527-00

AAR:0-704.15\% -00

A.4479-114114-0J

ANA79-114719.00

ก.4.73-10.4754-00

AAR73-10\%781-OA

MA/3-102783-03

AAA 7\$ - 104735-00

ААA73-104774-0A

AAA $B-701533-0$ A

A.A.75-10:50\%-n

AA4 $5-104 ; 37-0 B$

AAA73-105132-0B

AAA78-1051?8-0A

AAA78-1150? - 00

AAA 78-105129-00

AA.173-1150?2-100

AAn73-?14009-60

म․ำ $8=1117 ? 2-90$
Suh. Assy.

Marx-Cap.citor

Blumbin

Marx-Capar itor

Marx-Capicitor

Marx Capditor

Marx Capacitor

War $x$-capact tor

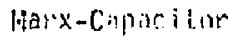

B]umiloin Carriege

Parx-Capacisor

$\Lambda$ Anplifier

950 KeV Oulput: 5uiteh

A50 keV Ontput Swi uid

$450 \mathrm{keV}$ outunt switch

150 KeV Output suitch

Laser Triggar d Dutpu

\section{Switch}

Loser Triggered output

Switich

Blutitein

Bluinlein

Blum?ein

Blumleia

Bluniein

Blungein

Brumlein

Blumlein

Bluniein

Blumlein, Pist

Bhisiein

Blumleig-itarx

Qlumiein

Harx-Caphetor

Blumiein
Detail

Side-R.H. (Smal1)

B Jock Resistor (1G)

side-L.H. (Smali)

Rod. Short

Spacor-Large

Block-Cancitor

Spitcore-sin? ?

Copp-Coijacitor

Adjustuent Scrom

Chann?-bass:

Scres, Cathode filomnt.

Ring, locel ing

Bloci, Pasictor

Capacita Eilting

Bot:

Pin Spalcer

Polation Pin

Rod-S apora, Ceparitur

i.urdidar, Resistor

Stoport-4a]f, Capacitor

Suprurt, Outar

Bose-prota. Flex

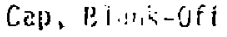

(ieps

Roi, chu: jirg

Plug-cop. Savity (LG)

Bkt, Cap, Sxitch

Ring, Coil Retainer

Center, Post

Plug, Invier Tube

Da11, Feedthril

Rod, anti-iotation 
Appendix A

Drawing No.

AAA79-114115-00

AAF $79-111116-00$

AAA79-114120-00

AAA79-171118-00

AAA79-174113-00

AAR79-114117-00

AAA79-174109-0A

AAA79-114129-00

AAA78-107856-0A

AAA78-106089-0C

MAA78-107360-0A

AAA78-107353-0A

AnA $78-10735900$

AAA78-116898-09

AAA79-111727-00

AAA78-114010-00

AAA78-111730-00

AAA78- 108456-00

MAA 7:. 1089:7.00

AAA78- $114067-00$

AAA78-108724-OA

AAA78 - $100925-00$

AAA78-108926-00

AAA78-108923-00

AAA73-108950-OA

AAA78 - $108934-00$

AAA78-108458-00

AAA79-708469-00
Sub. Assy.

Laser Triggered Dutput

Sivitch

Laser Triggered Output

Switch

Laser Triggered Output

Switch

Laser Triggered Output:

Sivitch

Laser Triggered Oulput

Switch

Laser Triggered Output

Styitch

Laser Triggered Output

Switch

Blumlein

A Arrplifier

A Amplifier

A Amplifier

A Amplitier

A Anplifier

Parx Capaitor

Electron Beam Accelerator

Marx-Capacitor

Blumiein

A Amplifier

B? umlein Carriage

Marx-Capacitor

Blumlein Carriage

Blumlein Carriage

Blumlein Carriage

Blumlein Carriage

Marx Capacitor

Marx Capacitor

A Amplifier

A Aniplifier
Detail

Lucite : inclow

Rear Plate (Cap, Cavity)

Flangle Fendthru

Cap. Driver

Inner Tube

Spacer Ring

Ring. Inner

Corona Ring

Brewster liount

Frame-Foil Window

Frane-l.lindor: (SIA)

Vindo:s Alapter

Plato, Filler Cell

Sirap, Ground

Harx Tank Assy

Insulator, Marx

Flange, Rist

Mount Incline $5^{\circ}$

Pow hi!justment saddle

Outlot Flanga Blumlein

Carriegs Trisck w/Angle

Carriage Trick

Front Aljustiont Block

Botton Adjustrient Block

Tank Assy (Small)

Base, plate

Stalk-Cathorie?

Cathode 
Appendix $A$

Drawing No.

AAA73-103457-0A

ARA\%S- - 208459-00

AAA79-106533-0A

AAA79-106531-OB

ANA79-106532-DA

AAN $12-105513-00$

AAR79-106520-OA

AAA73-706575-OA

AAA79-106524-0A

NAA79-174711-00

ANRY $10.4137-00$

AAA $19-114110-0 A$

A.AA78-1084\%:-0B

AAA79-106517-013

AAA79-106516-0B

AAA\%-108919-0R

A $1473-108455-00$

A.A478-10875h-00

AAA78-108471-0B

NAA78-108470-0A

AA473-104517-0A

AA478-706090-0A

AAA78-105091-00

AAn3S- 106097-0A

AAA79-109339-OB

AAA79-114172-00

ARA73-706083-OB

A4478-104516-0A

AAA73-1045 15-OA

AAA78-114011-00

A..A73-110145-0B
Sub. Assy.

A Anplifier

A Amplifier

150 KeV output switch

450 KeV Outpati Switchi

750 kev oulpui sivitch

$450 \mathrm{KeV}$ Output. Switch

450 KeV Output Sivitch

$450 \mathrm{kaV}$ 0utput. Switch

450 KeV Output Suibih

Laser Triggired 0iti 'ji

Sulitch

Electron biam Accelerator

Laser Triygered output

\section{Switch}

A Amplifier

$450 \mathrm{keV}$ Output Siritch

$450 \mathrm{KeV}$ Output. Suitch

Mar'x-Capde: i tor

A Amplifier

A Amplicier

A Amplifier

A Amplifier

Blumbin

A Anplifier

A Amplifier

A Airitifier

A Anpilifiur

Laser Triggered Dutpul Suitch

A Amplifier

Blumiein

Blumpein

Mary-Capacitor $\therefore$

A Allolifier
Detail

Moumt. Catholle

Spacer Cationde

Ring Imer R.ll.

Triggra Bhare fissy

Ring, Inner (L..H.)

Insulater Dise.

Ring, Onter

Rol, capacitar

Elertrorta Ring

Electrode ?irig

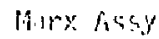

Trigurs plate

Hount Cotinolo Assy

ijudle Conduction

Triggar plato

Cover, Tans: (Stan1)

A Anjlificer Assy (Sheet 1)

A Amp ? isior Assy (Sheet $i$ )

Hous ing Dinile: Assy

Inner Comburtor Assy

Covor-Top

Insul]:or

Field Staper plate

I.j5: $6: ? 7$

Breweror bindod

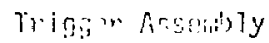

Hibatcir i Plat?

Copacit or-R.H.

Copacitor-L.H.

Indur:tor form.

Near :ylrinz? Incidence

Winclout 
Append ix A

Drawing No.

AAA7B-102833-OC

AR478-174007-00

AAA75-114007-00

AAA78. 104519-0C

MASO-103337-00

AAA78-104519-00

MAA78-108928-0A

AAA78-104519-OC
Sub. Assy.

Blumlein

Harx-Blumlein

Harx-Capacitor

Blun?ein

n-Star Laser

Blumle in

Blumiein Corriage

B 7um?ein
Detail

Duter Conductor

Outlet Flange Assy

Outlet-Flarge

Capacitor, Cavity

Mssembly

Capdcitor Cavity

Carriage Welded Assy

Capaciter Cavity 